\title{
Kinetic and modelling studies of NAD+ and poly(ethylene glycol)-bound NAD+ in horse liver alcohol dehydrogenase
}

\section{Citation for published version (APA):}

Vanhommerig, S. A. M., Sluyterman, L. A. A. E., \& Meijer, E. M. (1996). Kinetic and modelling studies of NAD+ and poly(ethylene glycol)-bound NAD+ in horse liver alcohol dehydrogenase. Biochimica et Biophysica Acta, Protein Structure and Molecular Enzymology, 1295(2), 125-138. https://doi.org/10.1016/0167-4838(96)00026-X

DOI:

10.1016/0167-4838(96)00026-X

Document status and date:

Published: 01/01/1996

\section{Document Version:}

Publisher's PDF, also known as Version of Record (includes final page, issue and volume numbers)

\section{Please check the document version of this publication:}

- A submitted manuscript is the version of the article upon submission and before peer-review. There can be important differences between the submitted version and the official published version of record. People interested in the research are advised to contact the author for the final version of the publication, or visit the $\mathrm{DOI}$ to the publisher's website.

- The final author version and the galley proof are versions of the publication after peer review.

- The final published version features the final layout of the paper including the volume, issue and page numbers.

Link to publication

\section{General rights}

Copyright and moral rights for the publications made accessible in the public portal are retained by the authors and/or other copyright owners and it is a condition of accessing publications that users recognise and abide by the legal requirements associated with these rights.

- Users may download and print one copy of any publication from the public portal for the purpose of private study or research.

- You may not further distribute the material or use it for any profit-making activity or commercial gain

- You may freely distribute the URL identifying the publication in the public portal.

If the publication is distributed under the terms of Article 25fa of the Dutch Copyright Act, indicated by the "Taverne" license above, please follow below link for the End User Agreement:

www.tue.nl/taverne

Take down policy

If you believe that this document breaches copyright please contact us at:

openaccess@tue.nl

providing details and we will investigate your claim. 


\title{
Kinetic and modelling studies of $\mathrm{NAD}^{+}$and poly( ethylene glycol) -bound $\mathrm{NAD}^{+}$in horse liver alcohol dehydrogenase
}

\author{
Sylvia A.M. Vanhommerig ", Lamoraal A.Æ. Sluyterman, Emmo M. Meijer \\ Laboratory of Orgranic Chemistry, Eindhoven University of Technology. P.O. Box 513, 5600 MB Eindhoven, The Netherlands \\ Received 24 August 1995; revised 14 February 1996; accepted 15 February 1996
}

\begin{abstract}
Poly(ethylene glycol)-bound nicotinamide adenine dinucleotide (PEG-NAD ${ }^{+}$) has been successfully employed in the continuous production of $\mathrm{L}$-amino acids from the corresponding $\alpha$-keto acids by stereospecific reductive amination. Like many other dehydrogenases also horse liver alcohol dehydrogenase (HLADH) appears to be active with PEG-NAD ${ }^{+}$as coenzyme, although the turnover number is three to four times lower. The possibilities were considered that the PEG-tail of a PEG-NAD ${ }^{+}$bound to one active site of the HLADH dimer prevents the binding of another PEG-NAD ${ }^{+}$to the second site, or that the PEG-tail causes destabilization of the active dimer. Both could be ruled out by kinetic studies. Neither can the observed lower intrinsic reactivity of PEG-NAD ${ }^{+}$account for the diminished activity of the enzyme. Molecular dynamics studies, on the other hand, show that the pulling action of the polymer chain shifts the NAD position in the active site in the outside direction, causing small but significant changes in the enzyme/coenzyme interactions of a sufficient extent to explain the experimental results.
\end{abstract}

Keywords: Poly(ethylene glycol)-bound $\mathrm{NAD}^{+}$; Alcohol dehydrogenase; Kinetic modelling; Reductive amination, stereospecific; Molecular dynamics and mechanics; (Horse liver)

\section{Introduction}

A number of synthetically useful enzymatic reactions require cofactors such as nicotinamide adenine dinucleotide $\left(\mathrm{NAD}^{+}\right)$. These cofactors are too expensive to be used as stoichiometric reagents in commercial applications. Regeneration of the cofactors from their reaction by-products is thus required to make the process economical. Many procedures have been suggested to achieve efficient coenzyme recycling, including enzymatic and non-enzymatic methods [1]. One of the systems investigated, the enzyme

Abbreviations: $\mathrm{NAD}^{+}$, nicotiramide adenine dinucleotide (oxidized form); NADH, nicotinamide adenine dinucleotide (reduced form); PEG$\mathrm{NAD}^{+}$, poly(ethylene glycol)-bound nicotinamide adenine dinucleotide (oxidized form); PEG-NADH, reduced form of PEG-NAD ${ }^{+}$; $\mathrm{NMN}^{+}$, nicotinamide mononucleotide; MM, molecular mechanics; MD, molecular dynamics; AMBER, assisted model building with energy refinement; PEG, poly(ethylene glycol); HLADH, horse liver alcohol dehydrogenase (EC 1.1.1.1); BSA, bovine serum albumin; DMSO, dimethyl sulfoxide; rms, root mean square; $\mathrm{EtO}^{-}$, ethanolate; $\mathrm{PrO}^{-}$, isopropanolate; IPA, isopropanol.

* Corresponding author. Fax: +31 402451036 . membrane reactor concept developed by Wandrey and co-workers $[2,3]$, shows commercially attractive features. For example, continuous production of L-amino acids from the corresponding $\alpha$-keto acids by stereospecific reductive amination has been achieved with little cofactor consumption in a membrane reactor in which $\mathrm{NAD}^{+}$is covalently linked to poly(ethylene glycol) (PEG-NAD ${ }^{+}$, Fig. 1) [4].

Many other dehydrogenases accept the PEG-NAD ${ }^{+}$as coenzyme. So far, glucose dehydrogenase is the only enzyme known that is not active with PEG-NAD ${ }^{+}$[5]. Until now, the observed activities of PEG-NAD ${ }^{+}$with dehydrogenases are not yet understood at the molecular level.

The $\mathrm{NAD}^{+} / \mathrm{NADH}$ dependent horse liver alcohol dehydrogenase (HLADH), which stereoselectively catalyses the interconversions of alcohols to their corresponding aldehyde/ketones and vice versa, seems an ideal candidate for studies aiming at the elucidation of coenzyme/apo-enzyme interactions. Many kinetic data and results from $X$-ray crystallographic studies on binary and ternary complexes are available for HLADH [6-13], making this enzyme one of the best characterized dehydrogenases. 


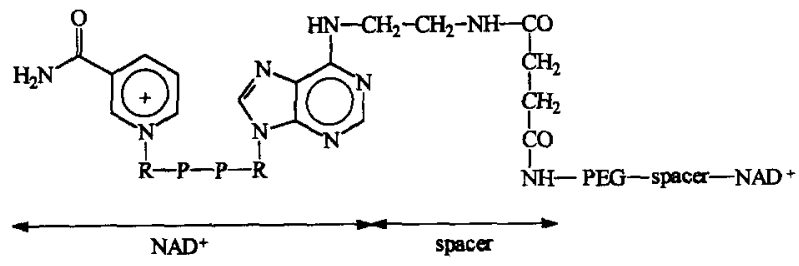

Fig. 1. Structure of polyethylene glycol bound $\mathrm{NAD}^{+} . \mathrm{R}=$ ribose, $\mathrm{P}=$ phosphate, $\mathrm{PEG}=$ polyethylene glycol $=\left(\mathrm{CH}_{2}-\mathrm{CH}_{2}-\mathrm{O}\right)_{n}$.

Several groups have performed modelling studies on this enzyme system, trying to obtain more details about the catalytic and structural features of HLADH [14-16].

In the past we have used a molecular mechanics approach to study in detail the interactions of the coenzyme $\mathrm{NAD}^{+}$and a number of analogues in the active site of HLADH, in order to understand the essential factors involved in the productive binding between coenzyme and apo-enzyme [17-20]. In this paper we present the results of detailed kinetic studies on HLADH with PEG-NAD ${ }^{+}$as coenzyme, and an extension of our modelling studies including molecular mechanics (MM) and dynamics (MD), to rationalize the kinetic data obtained.

\section{Materials and methods}

\subsection{Materials}

$\mathrm{HLADH}, \mathrm{NMN}^{+}$and $\beta-\mathrm{NAD}^{+}$were purchased from Sigma. PEG-NADH $\left(M_{\mathrm{r}}=20000\right)$ was supplied by Prof. Dr. C. Wandrey and Dr. U. Kragl from the Institute of Biotechnology in Jülich, prepared according to Ref. [21]. The coenzyme $\mathrm{NAD}^{+}$was lyophilised from distilled water. HLADH from Sigma (specific activity $1-2 \mathrm{U} / \mathrm{mg}$ ) was used because its ethanol content, less than $0.15 \%$, proved to be low enough not to disturb activity determinations using isopropanol as substrate, making extensive dialysis or gel filtration of the enzyme [22] superfluous. The PEG-NADH was oxidized to PEG-NAD $^{+}$as described by Bückmann et al. [21]. The PEG-NAD ${ }^{+}$was purified using a bacterial filter, with a pore size of $0.2 \mu \mathrm{m}$. The coenzyme concentrations were determined spectrophotometrically using the following absorption coefficients: $18000 \mathrm{M}^{-1} \mathrm{~cm}^{-1}$ at $\lambda_{\max }=260 \mathrm{~nm}$ for $\mathrm{NAD}^{+}, 21600$ $\mathrm{M}^{-1} \mathrm{~cm}^{-1}$ at $\lambda_{\max }=267.5 \mathrm{~nm}$ for PEG-NAD ${ }^{+}$and 6220 $M^{-1} \mathrm{~cm}^{-1}$ at $340 \mathrm{~nm}$ in case of the reduced forms. Sodium dithionite was purchased from Janssen Pharmaceutical (purity $\approx 80 \% ; \varepsilon=7000 \mathrm{M}^{-1} \mathrm{~cm}^{-1}$ ), potassium cyanide from Merck and Koshland reagent from Aldrich (purity $98 \% ; \epsilon=18000 \mathrm{M}^{-1} \mathrm{~cm}^{-1}$ at $\lambda=410 \mathrm{~nm}$ and $\mathrm{pH}$ 10).

\subsection{Kinetic measurements}

All kinetic experiments were carried out at $25^{\circ} \mathrm{C} \pm 0.1^{\circ} \mathrm{C}$ in $47 \mathrm{mM}$ phosphate buffer, $0.25 \mathrm{mM}$ EDTA, $\Gamma=0.1$.
The $\mathrm{pH}$ was adjusted to 8.0 with $\mathrm{KOH}$. A Perkin-Elmer $\mathrm{UV} / \mathrm{Vis}$ spectrophotometer Lambda $3 \mathrm{~B}$ was used. Steady-state kinetics were carried out with coenzyme saturation $\left(0.55 \mathrm{mM} \mathrm{NAD}^{+}\right.$or $\left.0.59 \mathrm{mM} \mathrm{PEG-NAD}{ }^{+}\right)$and a substrate concentration range from $1-10 \mathrm{mM}$ in the case of ethanol and $10-100 \mathrm{mM}$ in the case of isopropanol (see Appendix $\mathrm{A}$ for the equation used to determine the initial rates); the $\mathrm{NAD}^{+}$and $\mathrm{PEG}-\mathrm{NAD}^{+}$concentrations were varied between $5-55 \mu \mathrm{M}$ at a constant ethanol concentration of $10 \mathrm{mM}$. The change of absorption at $340 \mathrm{~nm}$ was measured. The enzyme concentrations ranged from $0.03-$ $0.52 \mu \mathrm{M}$ during the steady-state measurements. BSA was added to the enzyme stock solution to stabilize the HLADH. The interference of poly(ethylene glycol) in the steady-state kinetics was checked using $1 \mathrm{mM}$ PEG concentration (2\%, $\mathrm{w} / \mathrm{v}$ ), $10 \mathrm{mM}$ ethanol and $\mathrm{NAD}^{+}$or PEG-NAD ${ }^{+}$(varied between 5-500 $\mu \mathrm{M}$ ) as coenzyme.

\subsection{Formation of adducts}

The rates of formation of sulphinate adducts were determined at $20.1^{\circ} \mathrm{C}$ in a $\mathrm{Hi}$-Tech Scientific stopped-flow spectrophotometer SF-51. Equal amounts of an anaerobic $0.20 \mathrm{mM}$ sodium dithionite solution in $50 \mathrm{mM}$ Tris- $\mathrm{HCl}$ buffer ( $\mathrm{pH} 7.8$ ) and an anaerobic $1.32 \mathrm{mM}$ coenzyme solution in phosphate buffer ( $\mathrm{pH} \mathrm{8.2)}$ were mixed, under an argon flush. The total volume was $150 \mu \mathrm{l}$. The formation of the sulphinate adduct was followed spectrophotometrically by measuring the change in absorption at 353 $\mathrm{nm}\left(\varepsilon_{\text {adduct }}=3200 \mathrm{M}^{-1} \mathrm{~cm}^{-1}\right)$. All the solutions used were made anaerobic by repeatedly flushing with purified argon [23].

The formation of the cyanide adduct was carried out at $25^{\circ} \mathrm{C}$ in a $0.01 \mathrm{M} \mathrm{KCN}$ solution. The coenzyme concentration was $0.17 \mathrm{mM}$ in a total volume of $2.5 \mathrm{ml}$. The reactions were followed spectrophotometrically by measuring the increase in absorption at $325 \mathrm{~nm}\left(\epsilon_{\text {adduct }}=6300\right.$ $\mathrm{M}^{-1} \mathrm{~cm}^{-1}$ ) [24]. A Perkin-Elmer UV/Vis spectrophotometer Lambda 3B was used.

\subsection{Molecular mechanics and dynamics calculations}

Energy calculations, total energy-minimizations and molecular dynamics simulations were performed with the molecular mechanical simulation package AMBER 4.0 [25] on an Power Challenge SGI computer. The potential energy function used by AMBER is of the form:

$$
\begin{aligned}
V= & \sum_{\text {bonds }} k_{r}\left(r-r_{\mathrm{e}}\right)^{2}+\sum_{\text {angles }} k_{\theta}\left(\theta-\theta_{\mathrm{e}}\right)^{2} \\
& +\sum_{\text {dihedrals }} \frac{V_{n}}{2}(1+\cos [n \varphi-\gamma]) \\
& +\sum_{i<j}\left(\frac{A}{r_{i j}^{12}}-\frac{B}{r_{i j}^{6}}+\frac{q_{i} q_{j}}{r_{i j} \varepsilon}\right)+\sum_{\mathrm{H} \text { bonds }}\left(\frac{C}{r_{i j}^{12}}-\frac{D}{r_{i j}^{10}}\right)
\end{aligned}
$$


The crystallographic structure of the ternary complex of HLADH/NADH/DMSO [13] was used as a starting structure and obtained from the Protein Data Bank (PDB reference number $6 \mathrm{ADH})$. The cysteine residues 46,103 , 111 and 174 were defined as negatively charged cysteines, containing thiolate groups. All histidine residues were taken as HID except the His-51, which was taken HIP (diprotonated histidine). Ethanolate or isopropanolate was substituted at the position of DMSO. Nine water molecules were added manually, according to their subsequent presence in both the binary complex of HLADH (PDB file $5 \mathrm{ADH})$ [12] and the X-ray structure of HLADH with $\mathrm{NAD}^{+}$and pentafluorobenzyl alcohol [6]. Then water was added in a range of $2.9 \mathrm{~nm}$ around the catalytic zinc ion, applying a minimum distance of $0.26 \mathrm{~nm}$ between the oxygen atom of a water molecule and the heavy atoms of the enzyme complex, resulting in 1368 water residues in the shell around the enzyme. All water molecules were treated as TIP3P residues [26]. Since the enzyme is too large to be minimized completely during the calculations, the belly option was used so that only the amino acid residues within a radius of $1.5 \mathrm{~nm}$ around $\mathrm{NAD}^{+}$, the alcoholate, the catalytic zinc atom, $\mathrm{NAD}^{+}$and all water molecules were allowed to move freely (6825 atoms in the belly); but first the water molecules and the substrate were optimized, keeping the res: fixed.

The three-dimensional starting structure of PEG-NAD ${ }^{+}$ was constructed from the $\mathrm{X}$-ray $\mathrm{NAD}^{+}$geometry to which the PEG-residues were linked using the program QUANTA/CHARMM 3.3.2 [27]. Only 10 PEG residues plus the spacer group (see Fig. 1) were coupled to the exocyclic adenine- $\mathrm{NH}_{2}$ group. After the MD heating simulation the
PEG-tail is positioned for the main part of the time on the surface of the water shell.

All energy minimizations (MM-calculations, using 750 steps of steepest descent algorithm, followed by the conjugate gradient algorithm) were performed until the rms gradient value of the energy was less than $0.1 \mathrm{kcal} \AA^{-1}$, using a dielectric constant $\varepsilon$ of 1 and treating all $\mathrm{CH}, \mathrm{CH}_{2}$ and $\mathrm{CH}_{3}$ groups of the amino acids as united atoms. The non-bonded pair list had a cutoff of $12 \AA$ and was updated every 25 time steps. The water cap was restrained at the 29 $\AA$ boundary by a harmonic potential with a force constant of $0.5 \mathrm{kcal} \AA^{-1}$ (positional constraints). Atomic charges of the nicotinamide moiety, the negatively charged cysteines, $\mathrm{iPrO}^{-}$and of $\mathrm{EtO}^{-}$were derived from $6-31 \mathrm{G}^{*} / / 3-21 \mathrm{G}$ ab initio calculations (Appendix A Section A.2). The zinc ions carried a charge of 1.45 , according to the calculations by Tapia et al. [28]. Most harmonic force constants were obtained directly from the literature or extrapolated (see below, parametrization and Table 1) $[29,30]$.

The molecular dynamics (MD) simulations up to $90 \mathrm{ps}$ were carried out using a time step of $2.0 \mathrm{fs}$ and the SHAKE procedure to constrain all the bond lengths. The following protocol was used: a heating phase of 5 ps to a final temperature of $300 \mathrm{~K}$ followed by 35 ps of equilibration and finally an observation period of 50 ps ( 250 conformations for analysis). Analysis of atomic trajectories was achieved with the CARNAL program [31].

\subsection{Parametrization}

In order to maintain the tetracoordinated structure of the zinc ion, an explicit $\mathrm{Zn}-\mathrm{O}$ bond and explicit angles of

Table 1

Newly added AMBER force field parameters

\begin{tabular}{|c|c|c|c|}
\hline \multicolumn{4}{|c|}{ Non-bonded parameters for zinc } \\
\hline & $\mathrm{Zn}$ & $\varepsilon=0.10 \mathrm{kcal} \cdot \mathrm{mol}^{-1}$ & $r^{*}=1.40 \AA$ \\
\hline \multicolumn{4}{|c|}{ Angle parameters for $N A D^{+}$} \\
\hline & $\mathrm{CA}-\mathrm{C}-\mathrm{O}$ & $\theta=119.8^{\circ}$ & $k_{\sharp}=80 \mathrm{kcal} \cdot \mathrm{mol}^{-1} \cdot \mathrm{rad}^{-2}$ \\
\hline & $\mathrm{CA}-\mathrm{C}-\mathrm{N}$ & $\theta=115.7^{\circ}$ & $k_{\theta}=70 \mathrm{kcal} \cdot \mathrm{mol}^{-1} \cdot \mathrm{rad}^{-2}$ \\
\hline & $\mathrm{CA}-\mathrm{CA}-\mathrm{N}^{*}$ & $\theta=119.5^{\circ}$ & $k_{\theta}=70 \mathrm{kcal} \cdot \mathrm{mol}^{-1} \cdot \mathrm{rad}^{-2}$ \\
\hline & $\mathrm{CA}-\mathrm{N} "-\mathrm{CA}$ & $\theta=121.2^{\circ}$ & $k_{\mathrm{A}}=70 \mathrm{kcal} \cdot \mathrm{mol}^{-1} \cdot \mathrm{rad}^{-2}$ \\
\hline & $\mathrm{CA}-\mathrm{N}:-\mathrm{CT}$ & $\theta=120.6^{\circ}$ & $k_{\mathrm{A}}=70 \mathrm{kcal} \cdot \mathrm{mol}^{-1} \cdot \mathrm{rad}^{-2}$ \\
\hline \multicolumn{4}{|c|}{ Torsion parameters for $\mathrm{NAD}^{+}$} \\
\hline & $\mathrm{CA}-\mathrm{C} A_{L}-\mathrm{C}-\mathrm{O}$ & $\gamma=180^{\circ}$ & $V_{2} / 2=0.45 \mathrm{kcal} \cdot \mathrm{mol}^{-1}$ \\
\hline & & $\gamma=0^{\circ}$ & $V_{1} / 2=0.02 \mathrm{kcal} \cdot \mathrm{mol}^{-1}$ \\
\hline & $\mathrm{C} \#-\mathrm{CA}-\mathrm{C}-\mathrm{O}^{a}$ & $\gamma=180^{\circ}$ & $V_{2} / 2=0.45 \mathrm{kcal} \cdot \mathrm{mol}^{-1}$ \\
\hline & & $\gamma=180^{\circ}$ & $V_{1} / 2=0.02 \mathrm{kcal} \cdot \mathrm{mol}^{-1}$ \\
\hline & $\mathrm{CA}-\mathrm{C} A_{\imath}-\mathrm{C}-\mathrm{N}$ & $\gamma=180^{\circ}$ & $V_{2} / 2=0.45 \mathrm{kcal} \cdot \mathrm{mol}^{-1}$ \\
\hline & & $\gamma=180^{\circ}$ & $V_{1} / 2=0.02 \mathrm{kcal} \cdot \mathrm{mol}^{-1}$ \\
\hline & $\mathrm{C} \#-\mathrm{C} A-\mathrm{C}-\mathrm{N} a$ & $\gamma=180^{\circ}$ & $V_{2} / 2=0.45 \mathrm{kcal} \cdot \mathrm{mol}^{-1}$ \\
\hline & & $\gamma=0^{\circ}$ & $V_{1} / 2=0.02 \mathrm{kcal} \cdot \mathrm{mol}^{-1}$ \\
\hline \multicolumn{4}{|c|}{ Restraints to maintain tetracoordination around catalytic sinc } \\
\hline Bond & $\mathrm{Zn}-\mathrm{O}$ & $r=2.14 \AA$ & $k_{\mathrm{r}}=100 \mathrm{kcal} \cdot \mathrm{mol}^{-1} \cdot \mathrm{A}^{-2}$ \\
\hline Angle & $S-Z n-S$ & $\theta=132.6^{\circ}$ & $k_{\mathrm{\theta}}=50 \mathrm{kcal} \cdot \mathrm{mol}^{-1} \cdot \mathrm{rad}^{-2}$ \\
\hline Angle & $\mathrm{N}-\mathrm{Zn}-\mathrm{S}$ & $\theta=107.8^{\circ}$ & $k_{H}=50 \mathrm{kcal} \cdot \mathrm{mol}^{-1} \cdot \mathrm{rad}^{-2}$ \\
\hline Angle & $\mathrm{N}-\mathrm{Zn}-\mathrm{O}$ & $\theta=95.0^{\circ}$ & $k_{\theta}=50 \mathrm{kcal} \cdot \mathrm{mol}^{-1} \cdot \mathrm{rad}^{-2}$ \\
\hline
\end{tabular}

a $\mathrm{C \#}$ is the same atom type as $\mathrm{CA}$ and only used to describe the torsion of the carboxamide side chain. 
$\mathrm{N}-\mathrm{Zn}-\mathrm{S}, \mathrm{S}-\mathrm{Zn}-\mathrm{S}$ and $\mathrm{N}-\mathrm{Zn}-\mathrm{O}$ were inserted between the zinc ion and its ligands (cf. Table 1). The $k_{\mathrm{r}}$ of the $\mathrm{Zn}-\mathrm{O}$ bond is perhaps a little too low compared with the suggested value in such cases by Ref. [32]. Although they suggest a $r_{\text {eq }}=1.80 \AA$, we believe that $r_{\text {eq }}=2.14 \AA$ is justified, since the observed $\mathrm{Zn}-\mathrm{O}$ distance in several complexes of HLADH with water or an alcohol are all around this value of $2.14 \AA$. The parameters describing the dihedral barrier for the carboxamide orientation of the side chain of the nicotinamide moiety with $6-31 \mathrm{G}^{*}$ atom charges, were estimated as follows: $V_{1} / 2=0.08 \mathrm{~kJ} \mathrm{~mol}^{-1}$ $\left(0.02 \mathrm{kcal} \mathrm{mol}^{-1}\right)$ and $V_{2} / 2=1.88 \mathrm{~kJ} \mathrm{~mol}^{-1}(0.45 \mathrm{kcal}$ $\mathrm{mol}^{-1}$ ) [20]. This resulted in a rotational barrier of $12.6 \mathrm{~kJ}$ $\mathrm{mol}^{-1}$ around the $\mathrm{C} 3-\mathrm{C} 7$ bond of the nicotinamide moiety of the free coenzyme.

\section{Results and discussion}

\subsection{Kinetic results}

The kinetic behaviour of HLADH with both ethanol and isopropanol can be described by the conventional treatment of those cases in which the enzyme, coenzyme and substrate combine into a ternary complex [33-35], the reaction taking place in this complex. If $\mathrm{NAD}^{+}$is used as coenzyme and ethanol as substrate, the dissociation of the NADH from the enzyme is the rate limiting step, whereas in the case of the poor substrate isopropanol the rate of hydride-transfer is limiting as shown by pre steady-state measurements [36]. Table 2 summarizes the steady-state kinetic data obtained for $\mathrm{NAD}^{+}$and PEG-NAD ${ }^{+}\left(M_{\mathrm{r}}=\right.$ 20000 of the PEG-tail) with ethanol or isopropanol as substrate. The same mechanism as for $\mathrm{NAD}^{+}$is assumed to occur for PEG-NAD ${ }^{+}$. We found that HLADH exhibits substantially lower activity if PEG-NAD ${ }^{+}$is used instead of the native $\mathrm{NAD}^{+}$. The turnover number appears to be three times lower for PEG-NAD ${ }^{+} /$ethanol compared to $\mathrm{NAD}^{+} /$ethanol. With isopropanol $k_{\text {cat }}$ even drops by a factor of four. With most dehydrogenases similar results have been found [2-5,37]. Only in a few cases comparable activities for $\mathrm{NAD}^{+}$and $\mathrm{PEG}-\mathrm{NAD}^{+}$have been reported $[3,4]$.

The $K_{\mathrm{M}}$ value for PEG-NAD ${ }^{+}$is significantly larger than the $K_{\mathrm{M}}$ for $\mathrm{NAD}^{+}$, which has also been observed with other dehydrogenases $[2,5,39]$.

Since the PEG-NADH sample may contain up to $5 \%$ single substituted product (and thus a small amount of free, terminal $\mathrm{OH}$-groups), the interference of poly(ethylene glycol) in the ordinary enzymatic reaction was investigated. Based on experiments in which $2 \% \mathrm{w} / \mathrm{v}$ PEG $\left(M_{\mathrm{r}}=20000\right)$ was tested for its properties as substrate or inhibitor for HLADH, it could be concluded that the compound does not interfere in any way, neither with $\mathrm{NAD}^{+}$nor with PEG-NAD ${ }^{+}$.

In order to explain the kinetic results obtained for HLADH with PEG-NAD ${ }^{+}$as coenzyme we performed several studies including the determination of the intrinsic reactivity of PEG-NAD ${ }^{+}$, binding studies with the apo-enzyme, shifts in the monomer-dimer equilibrium of HLADH and modelling calculations directed at the coenzyme/apoenzyme interactions.

\subsection{Measurements of intrinsic reactivities}

The lower activity found with PEG-NAD ${ }^{+}$in enzymatic reactions with HLADH and many other dehydrogenases might be attributed to a lower intrinsic reactivity of PEG-NAD ${ }^{+}$. We therefore determined the intrinsic reactivities of $\mathrm{NAD}^{+}$and PEG-NAD ${ }^{+}$using sodium dithionite and potassium cyanide as reducing agents. These reducing agents form sulphinate and cyanide adducts with the cofactors $[23,24]$. From the results listed in Table 3 it is clear that PEG-NAD ${ }^{+}$shows a strongly reduced reactivity with both $\mathrm{S}_{2} \mathrm{O}_{4}^{2-}$ and $\mathrm{CN}^{-}(31 \%$ and $43 \%$ of the reactivity of $\mathrm{NAD}^{+}$, respectively).

From NMR measurements it is known that free NADH in an aqueous environment can adopt a folded conformation, in which stacking occurs between the nicotinamide and adenine rings [40]. Such intramolecular stacking may

Table 2

Kinetic constants of horse liver $\mathrm{ADH}$ using $\mathrm{NAD}^{+}$and PEG-NAD ${ }^{+}$respectively, as coenzymes

\begin{tabular}{|c|c|c|c|c|c|}
\hline Parameter & Units & $\mathrm{NAD}^{+}$ & & PEG-NAD $^{+}$ & \\
\hline$\overline{k_{\mathrm{cat}}(\mathrm{EtOH})}$ & $\mathrm{s}^{-1}$ & $1.14^{\mathrm{a}}$ & $(100 \%)$ & 0.36 & $(32 \%)$ \\
\hline$k_{\text {cat }}($ IPA $)$ & $s^{-1}$ & 0.15 & $(13 \%)$ & 0.038 & $(3 \%)$ \\
\hline$K_{\mathrm{M}}\left(\mathrm{NAD}^{+}\right)^{\mathrm{b}}$ & $\mu \mathrm{M}$ & 16.3 & & 62.0 & \\
\hline$K_{\mathrm{M}}(\mathrm{EtOH})$ & $\mathrm{mM}$ & 0.46 & & 1.13 & \\
\hline$K_{\mathrm{M}}(\mathrm{IPA})$ & $\mathrm{mM}$ & 12.3 & & 16.8 & \\
\hline$k_{\text {cat }}(\mathrm{EtOH}) / \mathrm{K}_{\mathrm{M}}(\mathrm{EtOH})$ & $\mathrm{s}^{-1} \mathrm{mM}^{-1}$ & 2.48 & $(100 \%)$ & 0.32 & $(13 \%)$ \\
\hline$k_{\text {cat }}($ IPA $) / K_{M}($ IPA $)$ & $\mathrm{s}^{-1} \mathrm{mM}^{-1}$ & 0.012 & $(4.8 \% 0)$ & 0.0023 & $(0.9 \% c)$ \\
\hline
\end{tabular}

Initial velocities with varying concentrations of coenzymes or substrates were determined at $25^{\circ} \mathrm{C}$, measuring the increase in absorbance at $340 \mathrm{~nm}$. Standard errors for the estimated $k_{\text {cat }}$ and $K_{\mathrm{M}}$ values from a fit with HYPER [38] were less than 7\% and 20\%, respectively of the reported values.

${ }^{a}$ This corresponds with a specific activity of the enzyme preparation of $1.6 \mathrm{U} / \mathrm{mg}$. A preparation of $6 \mathrm{U} / \mathrm{mg}$ [39] would accordingly have produced $k_{\mathrm{cat}}(\mathrm{EtOH})$ of $4.3 \mathrm{~s}^{-1}$.

${ }^{b}$ Determined with an ethanol concentration of $10 \mathrm{mM}$. 
Table 3

Determination of the intrinsic reactivities for various coenzymes. The formation of the sulfinate and cyanide adducts were followed spectrophotometrically at $353 \mathrm{~nm}$ and $325 \mathrm{~nm}$ respectively

\begin{tabular}{lll}
\hline Coenzyme & Relative & Relative \\
& $k\left(\mathrm{SO}_{2}^{-}\right), \%$ & $k\left(\mathrm{CN}^{-}\right), \%$ \\
\hline $\mathrm{NAD}^{+}$ & $100^{\mathrm{a}}$ & $100^{\mathrm{a}}$ \\
${\mathrm{PEG}-\mathrm{NAD}^{+}}^{+}$ & 31 & 43 \\
$\mathrm{NMN}^{+}$ & 43 & 59 \\
\hline
\end{tabular}

${ }^{a}$ The absolute rates at $0.1 \mathrm{mM}$ dithionite and $10 \mathrm{mM} \mathrm{KCN}$ were $0.02 \mathrm{~s}^{-1}$ and $0.0012 \mathrm{Abs} \cdot$ units $^{-1} \mathrm{~s}^{-1}$, respectively.

very well enhance the reactivity of $\mathrm{NAD}^{+}$, as is nicely illustrated by the results obtained for the nicotinamide mononucleotide $\left(\mathrm{NMN}^{+}\right)$, lacking the adenoside part of $\mathrm{NAD}^{+}$(see Table 3 ). It is conceivable that the poly(ethylene glycol) tail attached to the adenine of PEG-NAD ${ }^{+}$ prevents the stacking phenomenon in PEG-NAD ${ }^{+}$, resulting in the lower intrinsic reactivity observed in solutions in the absence of enzyme ${ }^{1}$. It can therefore be argued that the reactivities of $\mathrm{NAD}^{+}$and PEG-NAD ${ }^{+}$, once bound in the active site of the apo-enzyme, do not differ that much; in contrast with the corformational behaviour of free $\mathrm{NAD}^{+}$, the coenzyme binds in an extended conformation to HLADH as can be seen in the X-ray structure $[13,41]$.

\subsection{Binding studies}

The HLADH dimer consists of two subunits, both of which contain one coenzyme binding site and one substrate binding site. Normally, two $\mathrm{NAD}^{+}$residues bind to the HLADH dimer in the coenzyme binding sites, plus two alcohol molecules in the substrate binding pockets. However, either by interactions of two PEG-chains, or after the binding of one PEG-NAD ${ }^{+}$molecule to a HLADH dimer, steric hindrance from the poly(ethylene glycol) tail, dangling outside the enzyme, with the second site might occur. From experimental data and a mathematical description concerning PEG-properties by Kambe et al. [42,43], it was calculated that the hydrodynamic radius $R_{\mathrm{h}}$ of poly(ethylene glycol) with a $M_{\mathrm{r}}$ of 20000 is $78 \AA$. As the linear distance between the entrances of the coenzyme pockets in the dimer is $38 \AA$, binding of a second PEG$\mathrm{NAD}^{+}$might be prevented by steric hindrance exerted by the tail of the first bound PEG-NAD ${ }^{+}$. Therefore, the number of coenzyme binding sites available in HLADH after binding of one PEG-NAD ${ }^{+}$molecule were checked.

\footnotetext{
'Unfortunately we were unable to carry out 'H-NMR experiments on PEG-NAD ${ }^{+}$or PEG-NADH. Due to the limited solubility of the polymer bound $\mathrm{NAD}^{+}$, the $\mathrm{H} 4$ signals could not be measured and no further information about the occurrence of the folded conformation of PEG$\mathrm{NAD}^{+}$could be obtained.
}

There are three possibilities altogether after the binding of the first PEG-NAD ${ }^{+}$.

(1) A second PEG-NAD ${ }^{+}$is able to bind.

(2) Only $\mathrm{NAD}^{+}$is able to bind in the other coenzyme binding site, but not a second PEG-NAD ${ }^{+}$.

(3) The second coenzyme binding site can neither bind PEG-NAD ${ }^{+}$nor $\mathrm{NAD}^{+}$.

Distinction could be made between options $1 / 3$ and 2 by measuring the competition between $\mathrm{NAD}^{+}$and PEG$\mathrm{NAD}^{+}$(See Appendix A for theoretical background). This competition was measured by determining the activity at constant saturating PEG-NAD ${ }^{+}$concentration and various subsaturating $\mathrm{NAD}^{+}$concentrations. Fig. 2 shows the theoretical relative rates of coenzyme conversion for the options $1 / 3$ and 2 . If option 2 is operative and all dimers contain only one PEG-NAD ${ }^{+}$at saturating concentration, each dimer still has one coenzyme site available for binding $\mathrm{NAD}^{+}$. Adding $\mathrm{NAD}^{+}$should therefore cause a strong increase in rate, the more so as $\mathrm{NAD}^{+}$is more active than PEG-NAD $^{+}$. If on the other hand options 1 or 3 are operative, the increase in rate will be limited, being due only to a partial, competitive replacement of PEG-NAD ${ }^{+}$ by more reactive $\mathrm{NAD}^{+}$.

Actually, the experimental results, in which both $\mathrm{NAD}^{+}$ and PEG-NAD ${ }^{+}$are exposed simultaneously to HLADH (see Fig. 2), are in perfect agreement with options 1 and 3, excluding option 2 .

Even if the polymer chain is confined within the volume of its hydrodynamic radius, (vide supra), its concentration can be calculated to be only $1.8 \% \mathrm{w} / \mathrm{v}$, i.e., this is the highest possible concentration of the polymer of the tail of PEG-NAD ${ }^{+}$bound at the first site that could occur at the second binding site, low enough not to prevent passage of ordinary $\mathrm{NAD}^{+}$. As already mentioned in the section dealing with the kinetic results, $2 \% \mathrm{w} / \mathrm{v}$ PEG in the bulk solution indeed does not affect the reaction rate. Therefore option 3 does not occur either, retaining option 1.

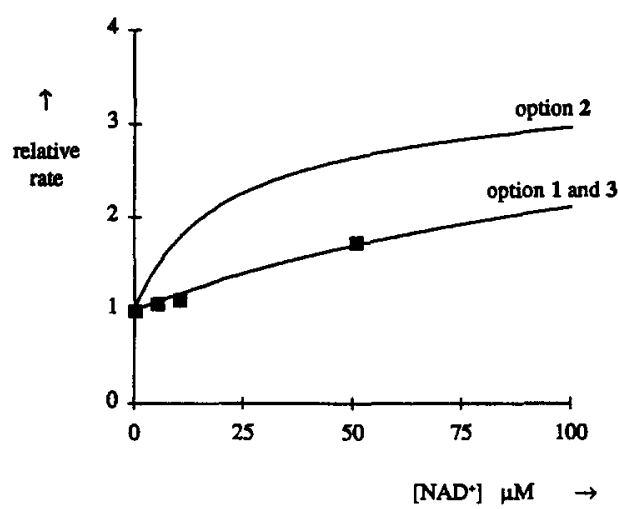

Fig. 2. Competition experiments between $\mathrm{NAD}^{+}$and PEG-NAD ${ }^{+}$; calculated (lines, calculated using the equations in Appendix A) and experimental relative rates ( $\boldsymbol{E})$, using a constant, high concentration of PEG$\mathrm{NAD}^{+}(0.51 \mathrm{mM})$. 
The remote possibility might be considered that, despite of HLADH being no allosteric enzyme, the nonoptimal binding of the NAD part of PEG-NAD ${ }^{+}$is transmitted to the other site, causing a similar lower affinity for NAD there. If such were the case, the observed rates would have been intermediate between the two curves in Fig. 2. This possibility can therefore be excluded too.

In summary, the conclusion can be drawn that the poly(ethylene glycol) tail of PEG-NAD ${ }^{+}$does not interfere with the coenzyme binding to both sites of HLADH.

\subsection{Check of the HLADH monomer-dimer equilibrium}

It is known from immobilization experiments that HLADH is active only as a dimer [44]. The low activity with PEG-NAD ${ }^{+}$might therefore be caused by an unfavourable shift in the monomer-dimer equilibrium, producing a partial dissociation of the dimer under the assay conditions. If such a equilibrium disturbance occurs, a decrease of the enzyme concentration at a constant PEG$\mathrm{NAD}^{+}$concentration would result in a larger amount of inactive HLADH monomer, implying a non-linear enzyme activity vs. enzyme concentration relationship. This possibility was checked by measuring the activity as a function of enzyme concentration in the relevant range of $0.03-0.15$ $\mu \mathrm{M}$, using ethanol as substrate. Since both coenzymes $\left(\mathrm{PEG}-\mathrm{NAD}^{+}\right.$and $\mathrm{NAD}^{+}$) proved to exhibit a linear relationship (results not shown), an equilibrium shift in the presence of PEG-NAD ${ }^{+}$in the enzyme concentration range concerned, can be ruled out.

All factors investigated thus far are unable to explain the three to four times lower activity of PEG-NAD ${ }^{+}$. The change in $k_{\text {cat }}$ (ethanol) suggests that the interaction between enzyme/coenzyme has changed. We therefore examined the possibility that the PEG-tail affects the interactions of the $\mathrm{NAD}^{+}$with the enzyme pocket by carrying out modelling calculations.

\subsection{Modelling calculations}

In the past, a molecular mechanics approach has been used to study in detail the interactions of the coenzyme $\mathrm{NAD}^{+}$and a number of analogues in the active site of HLADH, in order to understand the essential factors involved in the productive binding between coenzyme and apo-enzyme [17-19,45]. It seemed worthwhile, however, to reconsider their results, utilizing recent $\mathrm{X}$-ray data that show up more water molecules. In the following paragraph we present the results of improved modelling studies, including molecular mechanics (MM) and molecular dynamics (MD), to rationalize the kinetic data obtained.

Several X-ray crystallographic structures of binary and ternary complexes have been determined of HLADH [6-13] which can be used as starting structures for MD-studies aiming at the elucidation of coenzyme/apo-enzyme interactions. The simulations with $\mathrm{NADH}, \mathrm{NAD}^{+}$and PEG-
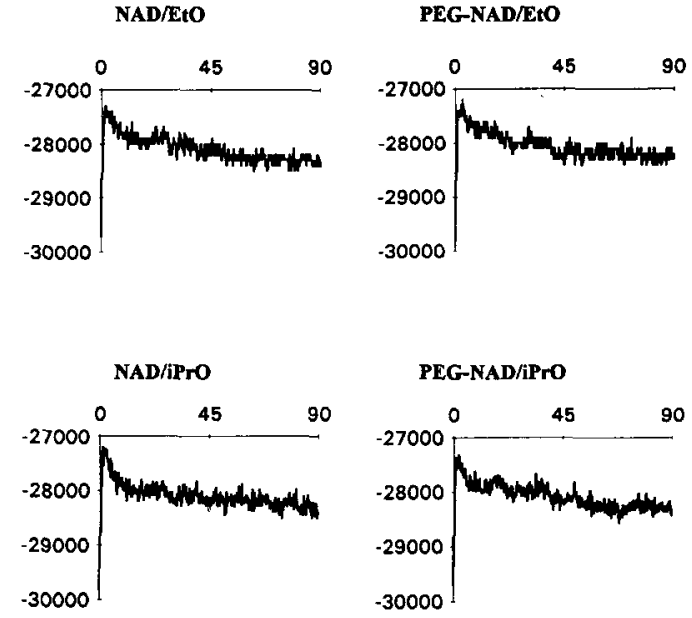

Fig. 3. The total potential (in $\mathrm{kcal} \mathrm{mol}^{-1}$ ) energy versus time (in ps). On the left for the $\mathrm{NAD}^{+} / \mathrm{RO}^{-}$complexes; on the right for the PEG$\mathrm{NAD}^{+} / \mathrm{RO}^{-}$complexes.

$\mathrm{NAD}^{+}$positioned in the ternary complexes of $\mathrm{HLADH} / \mathrm{DMSO} /$ coenzyme, $\mathrm{HLADH} / \mathrm{EtO}^{-} /$coenzyme and $\mathrm{HLADH} / \mathrm{iPrO}^{-} /$coenzyme, using the ternary crystal complex 6ADH [13], will now be discussed.

\subsection{Course of the simulations}

Variations of the total potential energy of the MD-alkoxide complexes as a function of time are reported in Fig. 3 . First the system is being warmed up $(300 \mathrm{~K})$ and the energy increases rapidly. Then in the next 45 ps the energy decreases and reaches an equilibrium after $\pm 60 \mathrm{ps}$ and fluctuates with small deviations around a mean value during the rest of the simulation. Analyses based on the $40-90$ ps period respectively the 50-90 ps period, did not lead to different results. Therefore, we used the data obtained from the $40-90$ ps analysis period.

\subsection{Overall structure}

The minimized (PEG-)NAD ${ }^{+}$structures have a rms deviation of the backbone atoms of the X-ray structures of $0.6 \AA$ for all complexes compared with the X-ray structure. In contrast with the MM geometries, the MD simulations of $\mathrm{NAD}^{+}$and PEG-NAD ${ }^{+}$complexes (collected from 40-90 ps simulations) show some differences compared with the original $\mathrm{X}$-ray structure, although the overall 3-dimensional structure is maintained (see Fig. 4). It is worth mentioning that between the subunits of the X-ray structure of HLADH/NADH/DMSO rms differences have been observed for the main and side chain atoms of 0.7 and $1.0 \AA$, respectively [13]. In the recently determined ternary crystal structure with pentafluoro benzylalcohol a rms difference of $0.24 \AA$ between the two subunits has been observed [6].

In Fig. 5 the average rms deviation of the backbone atoms during the $40-90$ ps MD simulation are shown 


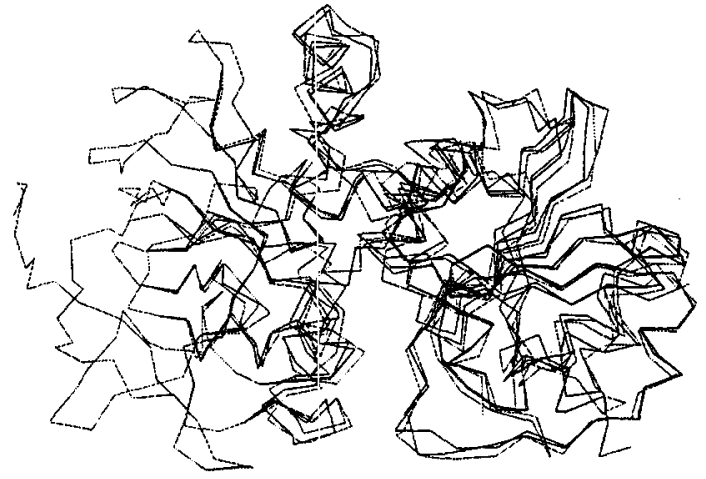

Fig. 4. MD-averaged structures of the $\mathrm{NAD}^{+} / \mathrm{EtO}^{-}(---)$and PEG-NAD ${ }^{+} / \mathrm{EtO}^{-}$(—) complex and the crystal structure [13] $(--)$. The left side is fixed during the calculations.

(only the atoms included in the belly option are included in the rms deviation). In both cases a plateau has been reached: the plateau for the $\mathrm{NAD}^{+} / \mathrm{EtO}^{-}$complex is higher than the one for $\mathrm{PEG}-\mathrm{NAD}^{+} / \mathrm{EtO}^{-}(1.66 \AA$ versus $1.28 \AA$ ). Thus the MD-averaged $\mathrm{NAD}^{+}$complex happens to be further away from the original X-ray structure. A similar situation exists for the $\mathrm{iPrO}^{-}$complexes (see Fig. 5). The oxygen atoms of the nine water molecules explicitly added in the active site show rms deviations from 1.0 to $4.3 \AA$. Similar rms deviations as reported above, have been communicated by other groups performing MD simulations on proteins [46].
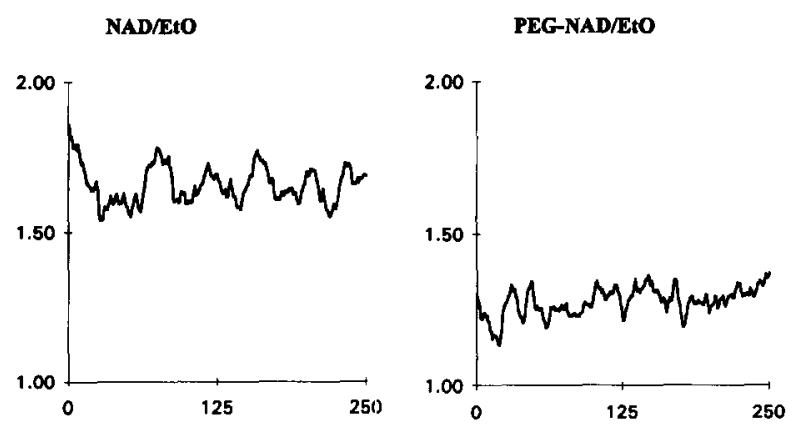

NAD/APrO

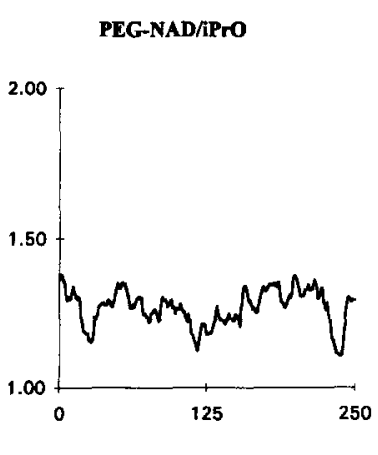

Fig. 5. The rms deviations (in $\AA$ ) of the backbone atoms for the 250 conformations over $40-90$ ps simulation period. On the left the values for the $\mathrm{NAD}^{+}$complexes; on the right the ones for the PEG-NAD ${ }^{+}$complexes.

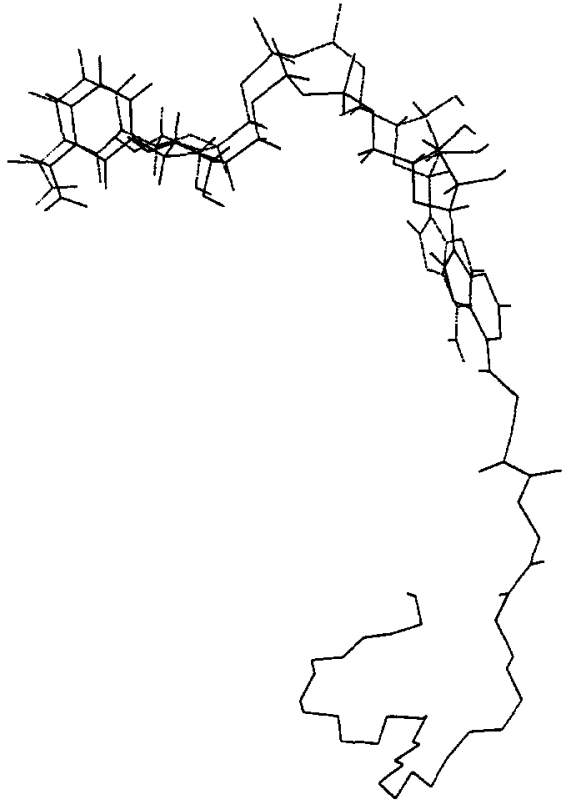

Fig. 6. Stick plot of the MD averaged structures of $\mathrm{NAD}^{+}(--)$and PEG-NAD ${ }^{+}$(— ) from the $\mathrm{iPrO}^{-}$complexes.

\subsection{Change in the coenzyme position}

The primary effect of the PEG-tail is quite evident in Fig. 6, which shows the positions of $\mathrm{NAD}^{+}$and PEG$\mathrm{NAD}^{+}$, in case $\mathrm{iPrO}^{-}$is substrate. It is apparent that the polymer tail pulls the adenine moiety in the outside direction by about $2 \AA$, dragging along with it the other parts of the coenzyme. A similar results was obtained with ethanol as substrate. This primary effect will of course induce small but significant conformational changes in the coenzyme itself and in the surrounding peptide chain. Some of these will next be treated in detail.

The outer layer of the enzyme complex is not optimally simulated during the calculations, due to the limited number of water molecules around the surface of the enzyme. The polymer tail used in the calculations is relative small (only 10 ethylene glycol residues versus over 400 in the kinetic experiments) and the 'pulling effect' can be expected to be larger when a longer polymer tail is applied. Since a larger water shell around the enzyme surface (and thus around the PEG tail) would diminish this pulling effect, we assume that both errors will sufficiently compensate each other to provide a qualitatively correct picture.

\subsection{Changes in the coenzyme conformation}

In addition to the shift in position of PEG-NAD ${ }^{+}$ shown in Fig. 6, MD results exhibit changes for some of the torsional angles (see Table 4). Most pronounced are those of more than $100^{\circ}$ in the case of PEG-NAD ${ }^{+} / \mathrm{EtO}^{-}$ for the torsional angles $\zeta_{\mathrm{N}}, \zeta_{\mathrm{A}}$ and $\alpha_{\mathrm{A}}$ (Fig. 7), all around 
Table 4

Overview of torsion angles a (in degrees) for $\mathrm{NAD}^{+}, \mathrm{PEG}^{\mathrm{N}} \mathrm{NAD}^{+}$as derived from modelling calculations (MM and $\mathrm{MD}$ ), and the $\mathrm{X}$-ray structure (NADH/DMSO/HLADH) [13]

\begin{tabular}{|c|c|c|c|c|c|c|c|c|c|c|c|}
\hline Coenzyme & $\theta$ & $\chi_{N}$ & $\gamma_{N}$ & $\beta_{\mathrm{N}}$ & $\alpha_{\mathrm{N}}$ & $\zeta_{N}$ & $\zeta_{\mathrm{A}}$ & $\alpha_{\mathrm{A}}$ & $\beta_{\mathrm{A}}$ & $\gamma_{\mathrm{A}}$ & $\chi_{\mathrm{A}}$ \\
\hline NADH (X-ray) & 34 & 258 & 39 & 214 & 59 & 207 & 85 & 106 & 147 & 281 & 264 \\
\hline \multicolumn{12}{|l|}{$M M$-results } \\
\hline $\mathrm{NAD}^{+} / \mathrm{iPrO}^{-}$ & 13 & 250 & 59 & 181 & 72 & 208 & 79 & 62 & 158 & 296 & 250 \\
\hline PEG-NAD ${ }^{+} / \mathrm{iPrO}^{-}$ & 13 & 251 & 59 & 183 & 69 & 209 & 71 & 61 & 146 & 309 & 254 \\
\hline $\mathrm{NAD}^{+} / \mathrm{EtO}^{-}$ & 13 & 250 & 58 & 181 & 71 & 206 & 80 & 61 & 157 & 294 & 250 \\
\hline $\mathrm{PEG}-\mathrm{NAD}^{+} / \mathrm{EtO}^{-}$ & 13 & 252 & 59 & 184 & 68 & 211 & 69 & 63 & 146 & 309 & 255 \\
\hline \multicolumn{12}{|l|}{ MD-results } \\
\hline $\mathrm{NAD}^{+} / \mathrm{iPrO}^{-}$ & 37 & 242 & 72 & 176 & 76 & 196 & 77 & 43 & 163 & 298 & 251 \\
\hline nPEG-NAD ${ }^{+} / \mathrm{iPrO}^{-}$ & 18 & 251 & 54 & 195 & 68 & 198 & 68 & 66 & 145 & 309 & 254 \\
\hline $\mathrm{NAD}^{+} / \mathrm{EtO}^{-}$ & 3 & 230 & 76 & 177 & 62 & 198 & 76 & 43 & 150 & 306 & 252 \\
\hline PEG-NAD ${ }^{+} / \mathrm{EtO}^{-}$ & 10 & 248 & 39 & 182 & 84 & 318 & 299 & 159 & 122 & 293 & 263 \\
\hline
\end{tabular}

The MD time-averaged values are taken from 250 conformations over $40-90 \mathrm{ps}$.

a According to IUPAC nomenclature [47].

the phosphate groups. It is remarkable that almost equal differences are observed between the two MD calculations of NADH/DMSO, the one with the limited belly and the one with the free subunit. This similarity suggests that in the present, approximately calculated, structure there are roughly two conformational states, of lower values of $\zeta_{N}$, $\zeta_{A}$ and $\alpha_{A}$, and of higher ones, differing little in their energy minima. Even the removal of a methyl group, i.e., proceeding from $\mathrm{PEG}-\mathrm{NAD}^{+} / \mathrm{iPrO}^{-}$to $\mathrm{PEG}$ $\mathrm{NAD}^{+} / \mathrm{EtO}^{-}$, is sufficient to tip the scales.

Another aspect of possible interest is the decrease of $\theta$ from $37^{\circ}$ to $18^{\circ}$ on adding the PEG-tail to $\mathrm{NAD}^{+} / \mathrm{iPrO}^{-}$ (Table 4). This will be discussed below.

Furthermore, we took a closer look at a few other relevant (torsional) angles. The rotation around the glycosidic bond (torsion $\chi_{\mathrm{N}}$ : $\mathrm{C} 2-\mathrm{N} 1-\mathrm{Cl}^{\prime}-\mathrm{O}^{\prime}$ ) indicates the extent of flexibility of the nicotinamide ring in the active site, and its positioning toward the ribose group. The average $\mathrm{MD}$-values (Table 4) for $\chi_{\mathrm{N}}$ of $230^{\circ}\left(\mathrm{NAD}^{+} / \mathrm{EtO}^{-}\right), 248^{\circ}$ $\left(\mathrm{PEG}-\mathrm{NAD}^{+} / \mathrm{EtO}^{-}\right) 242^{\circ}\left(\mathrm{NAD}^{+} / \mathrm{iPrO}^{-}\right)$and $251^{\circ}$ $\left(\mathrm{PEG}-\mathrm{NAD}^{+} / \mathrm{iPrO}^{-}\right)$, correspond to an anti conformation of the ribose and nicotinamide rings with all complexes simulated, similar to the conformation observed in the $\mathrm{X}$-ray structure [13].
The puckering of the ribose moieties is valued by the magnitude of the torsion angles $v_{2}(\mathrm{~N})$ and $v_{2}(\mathrm{~A})$ of the nicotinamide and adenine ribose respectively. The MM and MD structures all show $v_{2}(\mathrm{~N})$ values similar to the $\mathrm{X}$-ray value of $-37^{\circ}$ (Table 5). The $\nu_{2}(\mathrm{~A})$ values are

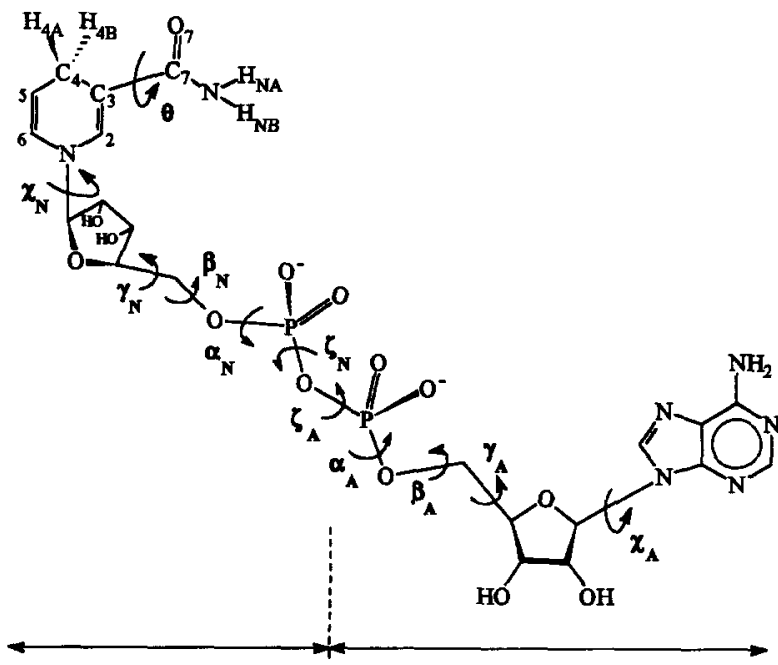

Fig. 7. Nomenclature of the coenzyme torsion angles and the atoms referred to in the text $[12,46]$

Table 5

Substrate-coenzyme distance and the puckering values of the nicotinamide ring and ribose rings

\begin{tabular}{|c|c|c|c|c|c|c|c|c|c|}
\hline & \multirow{2}{*}{$\begin{array}{l}\text { X-ray } \\
\text { NADH }\end{array}$} & \multicolumn{4}{|c|}{ Minimized structure } & \multicolumn{4}{|c|}{ MD-averaged structure } \\
\hline & & $\begin{array}{l}\mathrm{NAD}^{+} \\
\text {IPRO }^{-}\end{array}$ & $\begin{array}{l}\text { PEG-NAD } \\
\text { IRPO }^{+}\end{array}$ & $\begin{array}{l}\text { NAD }^{+} \\
\text {ETO }^{-}\end{array}$ & $\begin{array}{l}\text { PEG-NAD }{ }^{+} \\
\text {ETO }^{-}\end{array}$ & $\begin{array}{l}\mathrm{NAD}^{+} \\
\text {IPRO }^{-}\end{array}$ & $\begin{array}{l}\text { PEG-NAD } \\
\text { IPRO }^{-}\end{array}$ & $\begin{array}{l}\mathrm{NAD}^{+} \\
\mathrm{ETO}^{-}\end{array}$ & $\begin{array}{l}\text { PEG-NAD } \\
\text { ETO }^{-}\end{array}$ \\
\hline $\mathrm{C} 4(\mathrm{NAD})-\mathrm{C} 1\left(\mathrm{RO}^{-}\right)(\AA)$ & $4.18^{\mathrm{a}}$ & 3.37 & 3.38 & 3.42 & 3.44 & 3.46 & 3.57 & 3.56 & 3.57 \\
\hline$\alpha_{C}$ (degrees) & 0 & -4 & -4 & -3 & -4 & 4 & 7 & 7 & 10 \\
\hline$\alpha_{N}$ (degrees) & 0 & 3 & 3 & 3 & 3 & -2 & 1 & 2 & 2 \\
\hline$v_{2}(\mathrm{~N})$ (degrees) & -37 & -38 & -38 & -38 & -38 & -32 & -34 & -33 & -36 \\
\hline$v_{2}(\mathrm{~A})$ (degrees) & -37 & -24 & -21 & -24 & -22 & -20 & -15 & -20 & -21 \\
\hline
\end{tabular}

The MD time-averaged values are taken from 250 conformations over $40-90$ ps. The X-ray data are taken from the ternary complex with NADH /DMSO/HLADH [13].

The C4 (NAD)-S (DMSO) distance is used for the crystal structure. 
Table 6

RMS deviations of the MD-averaged structures from the crystal structure and RMS deviations between the two MD-averaged structures of the NAD ${ }^{+}$and PEG-NAD ${ }^{+}$complex

\begin{tabular}{|c|c|c|c|c|c|c|}
\hline & \multicolumn{4}{|c|}{ vs. Crystal structure } & \multicolumn{2}{|c|}{$\mathrm{MD} \mathrm{PEG}^{-N_{A D}{ }^{+}}$vs. $\mathrm{MD} \mathrm{NAD}^{+}$} \\
\hline & $\begin{array}{l}\mathrm{NAD}^{+} \\
\mathrm{iPrO}^{-}\end{array}$ & $\begin{array}{l}\mathrm{PEG}^{-\mathrm{NAD}^{+}} \\
\mathrm{iPrO}^{-}\end{array}$ & $\begin{array}{l}\mathrm{NAD}^{+} \\
\mathrm{EtO}^{-}\end{array}$ & $\begin{array}{l}\text { PEG-NAD }{ }^{+} \\
\mathrm{EtO}^{-}\end{array}$ & $\begin{array}{l}\mathrm{EtO}^{-} \\
\text {complex }\end{array}$ & $\begin{array}{l}\text { iPrO }^{-} \\
\text {complex }\end{array}$ \\
\hline \multicolumn{7}{|c|}{ Backbone atoms } \\
\hline & 1.45 & 1.27 & 1.66 & 1.28 & & \\
\hline \multicolumn{7}{|c|}{$C \alpha$ residues near coenzyme } \\
\hline 46 & 0.98 & 0.91 & 1.79 & 0.98 & 0.85 & 0.46 \\
\hline 47 & 0.98 & 0.57 & 1.92 & 0.63 & 1.30 & 0.41 \\
\hline 48 & 0.65 & 0.26 & 1.89 & 0.40 & 1.73 & 0.40 \\
\hline 51 & 0.47 & 0.20 & 1.56 & 0.41 & 1.55 & 0.32 \\
\hline 67 & 0.13 & 0.47 & 0.11 & 0.13 & 0.20 & 0.52 \\
\hline 174 & 1.06 & 0.90 & 1.17 & 0.84 & 0.86 & 0.84 \\
\hline 178 & 1.64 & 1.06 & 1.28 & 1.07 & 0.40 & 0.95 \\
\hline 202 & 0.78 & 0.81 & 0.98 & 0.68 & 1.10 & 1.46 \\
\hline 203 & 0.83 & 0.84 & 0.89 & 0.68 & 0.71 & 1.15 \\
\hline 292 & 0.33 & 0.33 & 0.35 & 0.43 & 0.63 & 0.43 \\
\hline 317 & 0.51 & 0.46 & 0.69 & 0.56 & 0.13 & 0.30 \\
\hline 319 & 1.91 & 1.86 & 1.31 & 1.55 & 0.25 & 0.57 \\
\hline 369 & 0.47 & 1.56 & 0.69 & 1.05 & 0.52 & 1.37 \\
\hline \multicolumn{7}{|c|}{$C \alpha$ residues near enzyme surface } \\
\hline 227 & 2.46 & 1.41 & 2.47 & 1.02 & 2.17 & 1.29 \\
\hline 248 & 3.83 & 1.36 & 6.39 & 2.28 & 4.42 & 3.36 \\
\hline 297 & 2.77 & 3.57 & 3.16 & 0.80 & 2.48 & 1.69 \\
\hline
\end{tabular}

smaller in the simulated complexes than in the X-ray structure.

The deformation angles $\alpha_{C}$ and $\alpha_{N}$ (defined as C2-C6C3-C4 and C3-C5-C6-N1, respectively) reflect the extent of bending of the nicotinamide ring towards a boat conformation (Table 5). This puckering of the nicotinamide ring places one of the C4-hydrogens of NADH in a pseudoaxial position, which could favour the hydride-transfer rate [48]. In Table 5 the average values for $\alpha_{C}$ and $\alpha_{N}$ for NAD ${ }^{+}$ are listed. Plots of these calculated $\alpha_{C}$ angles versus the calculated $\alpha_{N}$ angles are shown in Fig. 8. Only minor differences can be observed between the complexes.

\subsection{Changes of the polypeptide chain}

Due to some changes in the coenzyme position and geometry, the surrounding peptide chains also exhibits small conformational changes. Deviations of a few amino acids are listed in Table 6. Some C $\alpha$ 's of the coenzyme neighbouring amino acids are displaced by 1-2 $\AA$. Near

Table 7

Hydrogen-bonding distances (in $\AA$ ) and electrostatic interactions around the phosphate groups of the coenzyme for the time-averaged MD structures and crystal structure

\begin{tabular}{|c|c|c|c|c|c|}
\hline & $X$-ray & $\mathrm{NAD}^{+} \mathrm{iPrO}^{-}$ & 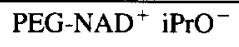 & $\mathrm{NAD}^{+} \mathrm{EtO}^{-}$ & 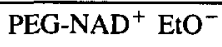 \\
\hline $\mathrm{O}^{2} \mathrm{P}_{\mathrm{N}}(\mathrm{NAD})-\mathrm{HN} 12(\operatorname{Arg}-369)$ & 2.95 & 1.72 & & 1.82 & 1.83 \\
\hline $\mathrm{O}^{1 \mathrm{P}_{\mathrm{N}}}$ (NAD)-H (WAT-757) & & & 1.74 & & \\
\hline $\mathrm{O}^{1} \mathrm{P}_{\mathrm{N}}(\mathrm{NAD})-\mathrm{H}(\mathrm{WAT})$ & & & 1.69 & & \\
\hline $\mathrm{O}^{1} \mathbf{P}_{\mathrm{N}}(\mathrm{NAD})-\mathrm{HN}(\mathrm{Val}-203)$ & & 1.99 & & 2.02 & \\
\hline $\mathrm{O}^{2} \mathrm{P}_{\mathrm{N}}(\mathrm{NAD})-\mathrm{HN}(\mathrm{Gly}-202)$ & 3.19 & & & & \\
\hline $\mathrm{O}^{2} \mathrm{P}_{\mathrm{N}}(\mathrm{NAD})-\mathrm{HN}(\mathrm{Val}-203)$ & 3.21 & & & & 1.83 \\
\hline $\mathrm{O}^{2} \mathrm{P}_{\mathrm{N}}(\mathrm{NAD})-\mathrm{HN}(204)$ & & 2.14 & 2.16 & 1.90 & 2.14 \\
\hline $\mathrm{O} \mathrm{P}_{\mathrm{A}}(\mathrm{NAD})-\mathrm{HN} 11(\mathrm{Arg}-47)$ & 2.91 & 1.68 & 1.98 & 1.70 & \\
\hline $\mathrm{O}^{1} \mathrm{P}_{\mathrm{A}}$ (NAD)-H (WAT) & & & & 1.83 & \\
\hline 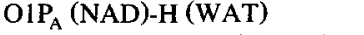 & & 1.88 & 2.07 & 1.83 & 1.64 \\
\hline $\mathrm{O}_{2} \mathrm{P}_{\mathrm{A}}$ (NAD)-HN11 (Arg-47) & & & & & 1.86 \\
\hline 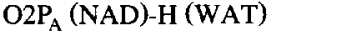 & & 2.39 & 1.65 & 1.75 & \\
\hline 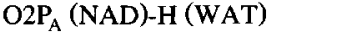 & & 2.11 & 2.21 & & 1.88 \\
\hline 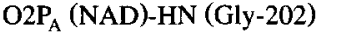 & & 2.32 & & & 2.19 \\
\hline $\mathrm{O}^{2} \mathrm{P}_{\mathrm{A}}$ (NAD)-HNZ1 (Lys-228) & 3.29 & 1.97 & & & \\
\hline
\end{tabular}

\footnotetext{
'WAT' denotes a water molecule.
} 


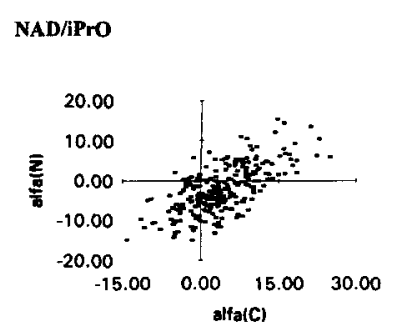

PEG-NAD/iPrO

NAD/EtO

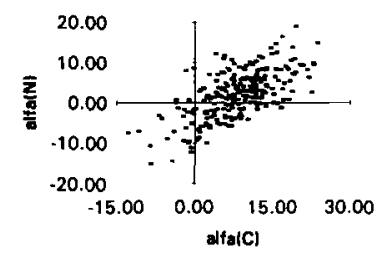

\section{PEG-NAD/EtO}

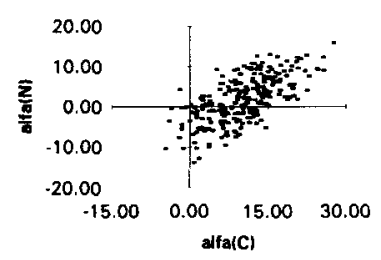

Fig. 8. The variations in of $\alpha_{C}$ versus $\alpha_{N}$ (in degrees) for the four MD simulations during the 40-90 ps sampling phase.

the enzyme surface sometimes large deviations are observed.

The average rms deviations between the MD-averaged structures of the surrounding peptides of the $\mathrm{NAD}^{+}$and the PEG-NAD ${ }^{+}$complexes are $0.81 \AA$ and $0.93 \AA$, respectively (Table 6). Though small, they are significant, because a second $\mathrm{NAD}^{+} / \mathrm{iPrO}^{-}$calculation showed a rms of only 0.32 deviation from the first one.

\subsection{Changes in the interactions between enzyme and coenzyme}

These changes can best be described in terms of $\mathrm{H}$ bonding patterns. The most pronounced differences occur around the phosphate groups. Near these phosphate groups strong electrostatic forces play an important role in the interaction between coenzyme and enzyme. The changes in interactions are evident from the hydrogen-bonds listed in Table 7. The encased $\mathrm{H}$-bonds are maintained during the simulations. The $\mathrm{NAD}^{+} / \mathrm{iPrO}^{-}$complex still has three $\mathrm{H}$-bonds as found in the X-ray structure; with PEG$\mathrm{NAD}^{+} / \mathrm{iPrO}^{-}$only 1 and with $\mathrm{NAD}^{+} / \mathrm{EtO}^{-}$and $\mathrm{PEG}-$

Table 8

The total interaction energies for (PEG-)NAD ${ }^{+}$derived from their corresponding MM calculations, and relative $k_{\text {cat }}$ values of coenzyme/substrate combinations when enzyme/coenzyme dissociation is rate-limiting

\begin{tabular}{|c|c|c|c|c|}
\hline & \multicolumn{2}{|c|}{$\mathrm{EtO}^{-}$complexes } & \multicolumn{2}{|c|}{ iPrO-complexes } \\
\hline & NAD & PEG-NAD & NAD & PEG-NAD \\
\hline$E_{\text {inter }}$ total a & -318 & -377 & -319 & -378 \\
\hline$E_{\text {inter }}$ alcohol $^{b}$ & -12 & -12 & -12 & -12 \\
\hline$E_{\text {inter }}$ enzyme ${ }^{\mathrm{c}}$ & -306 & -365 & -307 & -366 \\
\hline Relative $k_{\text {cat }}$ & 1 & 0.32 & & \\
\hline
\end{tabular}

\footnotetext{
"Total interaction energy of the coenzyme.

${ }^{\mathrm{b}} E_{\text {inter }}$ between the coenzyme and the alkoxide.

${ }^{\circ} E_{\text {inter }}$ between the coenzyme and the enzyme.
}

$\mathrm{NAD}^{+} / \mathrm{EtO}^{-} 2 \mathrm{H}$-bonds are similar to those found in the $\mathrm{X}$-ray structure. Furthermore three complexes have $\mathrm{H}$ bonds between $\mathrm{O} 2 \mathrm{P}_{\mathrm{A}}$ and two water molecules (which are also present in the refined crystal structure [41]) and only the PEG-NAD ${ }^{+} / \mathrm{EtO}^{-}$lacks these interactions. This is due to a new electrostatic interaction of the phosphate group with the Arg-47 side chain in the latter complex. In the $\mathrm{NAD}^{+} / \mathrm{EtO}^{-}$complex the HN11 of Arg-47 interacts with the OIP(A) oxygen (Table 7); in the case of PEG$\mathrm{NAD}^{+} / \mathrm{EtO}^{-}$this is replaced by $\mathrm{O} 2 \mathrm{P}(\mathrm{A})$. A similar change from $\mathrm{O} 1 \mathrm{P}(\mathrm{N})$ to $\mathrm{O} 2 \mathrm{P}(\mathrm{N})$ occurs in the hydrogen-bond with $\mathrm{HN}$ (203) in the $\mathrm{EtO}^{-}$complexes.

Although there is little change in the angles around the phosphate residues with $\mathrm{iPrO}^{-}$as substrate (see Section 3.10 , some of the interactions do change: hydrogen-bonds of O1P(N) with HN12 (Arg-369) and HN (203) (Table 7) are replaced by those with water, and those of $\mathrm{O} 2 \mathrm{P}(\mathrm{A})$ with HN (202) and HNZ1 (Lys-228) are removed.

All of these changes are likely to affect the binding of the coenzyme and the rates of the concomitant conformational changes, that have to take place during coenzyme association to and dissociation from the apo-enzyme, contributing to the observed decrease in $k_{\text {cat }}$ of ethanol oxidation.

It is generally accepted that the actual dissociation of the coenzyme from HLADH is preceded by a conformational change of the enzyme that widens the coenzyme cleft sufficiently to allow the coenzyme to pass outside [12]. As the conformational change is a relatively slow process, the overall dissociation rate of the coenzyme, 4.3 $\mathrm{s}^{-1}$ (see footnote ' $\mathrm{a}$ ' of Table 2) is considerably lower than the association/dissociation rates of ligands and enzymes in general. By this mechanism the various dissociation rates can be understood in terms of the interaction energies between enzyme and coenzyme (Table 8). In the first row the total energies are given. In order to have solely the interaction energies of enzyme and coenzyme, the interaction energies between coenzyme and substrate are substracted, yielding the third row. It is evident that in both the $\mathrm{EtO}^{-}$and $\mathrm{iPrO}^{-}$cases the energies of the native $\mathrm{NAD}^{+}$are consistently lower than those of PEG-NAD ${ }^{+}$. The trend (also detected with other $\mathrm{NAD}^{+}$analogues, not mentioned in this paper) is obvious enough; the stronger PEG-NAD ${ }^{+}$/enzyme interactions retard the widening of
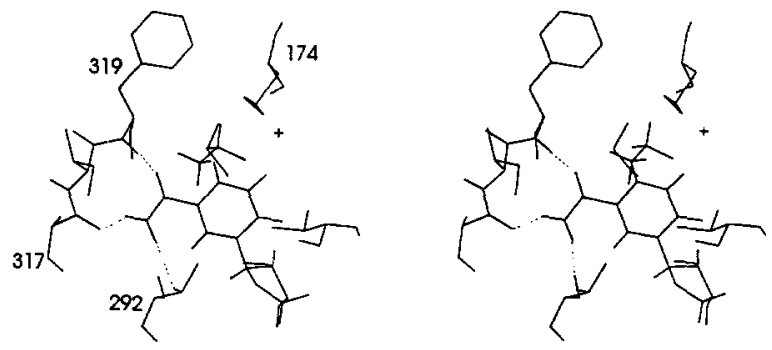

Fig. 9. Stereo pair of the active site of the crystal structure, showing the hydrogen-bonds of the carboxamide side chain with the enzyme. 
Table 9

Hydrogen-bonding pattern of the carboxamide side chain of the coenzyme with neighbouring amino acids

\begin{tabular}{|c|c|c|c|c|c|c|c|c|c|}
\hline & \multirow[t]{2}{*}{ X-ray } & \multicolumn{4}{|c|}{ Minimized structure } & \multicolumn{4}{|c|}{ MD-averaged structure } \\
\hline & & $\begin{array}{l}\mathrm{NAD}^{+} \\
\mathrm{IPRO}^{-}\end{array}$ & $\begin{array}{l}\text { PEG-NAD } \\
\text { IPRO }^{-}\end{array}$ & $\begin{array}{l}\text { NAD }^{+} \\
\text {ETO }^{-}\end{array}$ & $\begin{array}{l}\text { PEG-NAD } \\
\text { ETO }^{-}\end{array}$ & $\begin{array}{l}\mathrm{NAD}^{+} \\
\text {IPRO }^{-}\end{array}$ & $\begin{array}{l}\text { PEG-NAD } \\
\text { IPRO }^{-}\end{array}$ & $\begin{array}{l}\text { NAD }^{+} \\
\text {ETO }^{-}\end{array}$ & $\begin{array}{l}\text { PEG-NAD }^{+} \\
\text {ETO }^{-}\end{array}$ \\
\hline O7 (NAD)-HN (Phe-319) & 1.90 & 1.86 & 1.86 & 1.85 & 1.85 & 2.02 & 1.89 & 1.93 & 1.98 \\
\hline HNA (NAD)-O (Ala-317) & 1.96 & 1.99 & 1.97 & 1.99 & 1.97 & 1.90 & 1.91 & 1.87 & 1.93 \\
\hline HNB (NAD)-O (Val-292) & 1.73 & 1.87 & 1.89 & 1.87 & 1.88 & 2.51 & 1.89 & 1.95 & 1.92 \\
\hline
\end{tabular}

X-ray distances are taken from the crystal conformation [13]; MD distances are averaged for 250 conformations over $40-90$ ps. (Distances in $\AA$ ).

the cleft and therefore the dissociation, explaining the kinetic results with ethanol, where the enzyme-coenzyme dissociation rates are rate-limiting.

In the H-bonding interactions between the carboxamide side chain of the nicotinamide moiety and the enzyme, three amino acids are involved, namely Phe-319, Ala-317 and Val-292. They are shown in Fig. 9 and Table 9. $\mathrm{H}$-bonds are assigned if the donor (D)-acceptor (A) distance is, at least temporary, smaller than $3.5 \AA$ and the $\mathrm{D}-\mathrm{H}-\mathrm{A}$ angle value ranges between $90^{\circ}$ and $180^{\circ}$. An $\mathrm{H}-\mathrm{-}$ A bond of $\leq 2.5 \AA$ will be considered as being stable [49]

Fig. 10 shows the fluctuations in the three hydrogenbonds in these complexes. During the MD simulations all three $\mathrm{H}$-bonds are largely kept intact both in the $\mathrm{NAD}^{+}$ and in the PEG-NAD ${ }^{+}$complexes, with the exception of the $\mathrm{NAD}^{+} / \mathrm{iPrO}^{-} \mathrm{Val}-292$ bond, which is not quite stable (see also the hydride-transfer paragraph).

\subsection{The hydride-transfer}

Among the factors affecting the rate of hydride-transfer are the distance to be tided over and the out-of-plane orientation of the carboxamide side chain. As far as the first factor is concerned, the data in Table 5 are relevant. The average distances between the $\mathrm{C} 4$ of $\mathrm{NAD}^{+}$or PEG$\mathrm{NAD}^{+}$and the $\mathrm{Cl}$ atoms of $\mathrm{EtO}^{-}$and $\mathrm{iPrO}^{-}$turn out to be almost equal to the $3.40 \AA$ found by semiempirical calculations (results not explicitly shown here). The angles of approach $\mathrm{N} 1-\mathrm{C} 4-\mathrm{C} 1$ are also reasonably close; $107^{\circ}$ versus $114^{\circ}$ for ethanol, and $104^{\circ}$ versus $89^{\circ}$ for isopropanol for $\mathrm{MD}$ and quantum chemical calculations re-

\section{NAD/iPro}
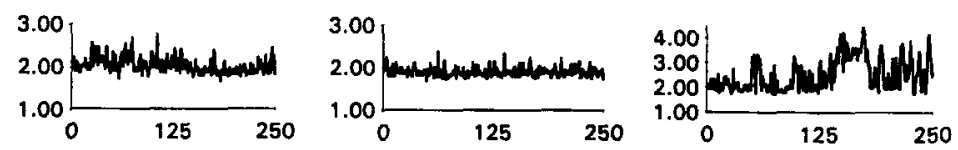

PEG-NAD/iPrO
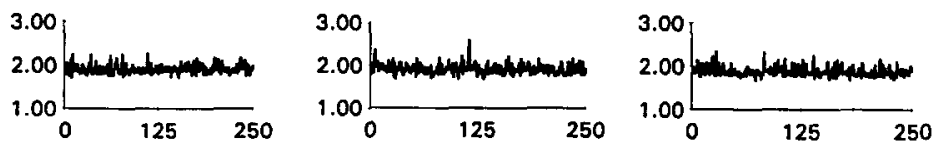

NAD/EtO
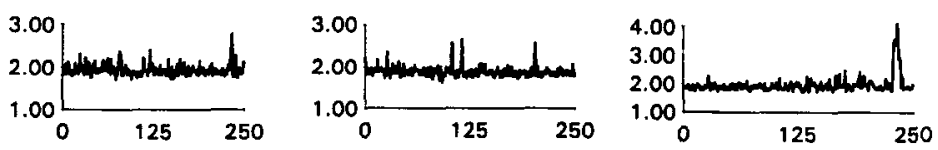

PEG-NAD/Eto
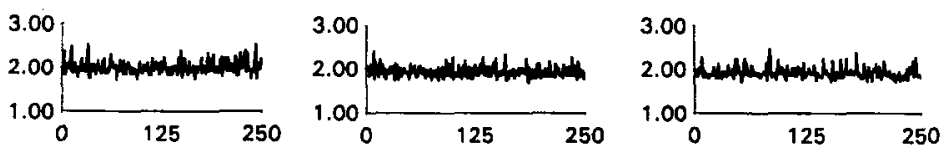

O7-HN (319)

HNA-O (317)

HNB-O (292)

Fig. 10. Hydrogen-bonding distance fluctuations (in $\AA$ ) between the carboxamide side chain and the HLADH residues Phe-319 (left), Ala-317 (middle) and Val-292 (right). 


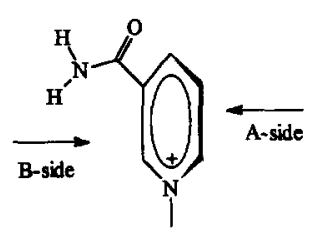

Fig. 11. The A- and B-side of the nicotinamide ring.

spectively. The PEG-tails do not change the MD values. Apparently all of these data do not provide an explanation for a reduced rate of hydrogen-transfer.

All dehydrogenases show high stereoselectivity towards the hydrogen to be transferred towards $\mathrm{C} 4$ of the nicotinamide ring. In A-specific enzymes like HLADH the pro- $R$ hydrogen atom $\mathrm{H}_{4 \mathrm{~A}}$ is transferred from NADH towards the substrate [50] (see Fig. 11). The $\mathrm{H}_{\mathrm{A}}$ and $\mathrm{H}_{\mathrm{B}}$ stereospecificity can be explained by the one-sided shielding by the apo-enzyme [51]. The possible relationship between the rate and the direction of hydride transfer and the syn orientation of the carbonyl dipole, has been extensively discussed [52-54]. In the X-ray structure of the ternary complex of HLADH/DMSO/NADH the carbonyl group of the side chain is rotated $34^{\circ}$ out of the plane of the pyridinium ring [13].

As far as the out-of-plane orientation is concerned, the out-of-plane values $\theta\left(\mathrm{O} 7-\mathrm{C} 7-\mathrm{C} 3-\mathrm{C} 4\right.$, Fig. 7) of $\mathrm{NAD}^{+}$ and PEG-NAD ${ }^{+}$complexes during the simulation period are shown in Fig. 12. For the $\mathrm{NAD}^{+} / \mathrm{iPrO}^{-}$complex a time-weighted average value of $32^{\circ}$ (Table 4) was calculated, i.e., a positioning of the carboxamide side chain on the A-side of the nicotinamide plane, which is in nice agreement with the observed $\mathrm{X}$-ray value of $34^{\circ}$ and the $30^{\circ}$ calculated by semiempirical studies [55]. On the other hand, the fluctuations in $\theta$ in this case (left top of Fig. 12) are larger than those of the other complexes. These fluctua-
NAD/PrO

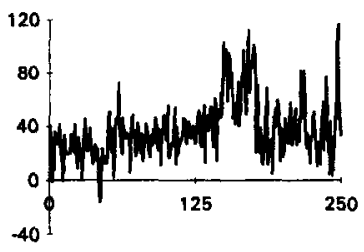

NAD/EtO

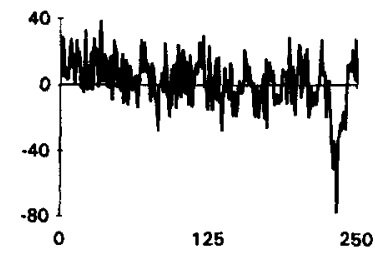

PEG-NAD/RPO

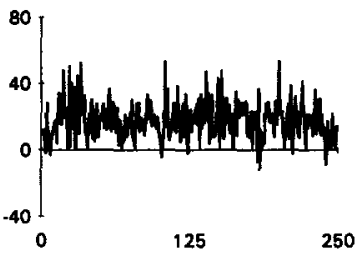

PEG-NAD/Eto

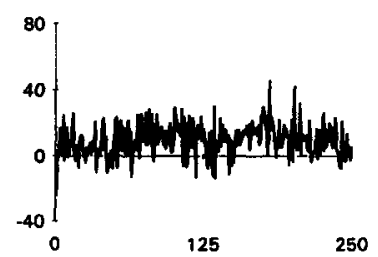

Fig. 12. Variation of $\theta$ (in degrees) of (PEG-)NAD ${ }^{+}$in HLADH for the 250 conformations during the $40-90$ ps sampling phase. tions are accompanied by lengthening of the H-bond with Val-292 (right top of Fig. 10).

Apparently the positioning of the carboxamide side chain is quite flexible.

The $\mathrm{iPrO}^{-}$complex with the PEG-NAD ${ }^{+}$coenzyme has a smaller average $\theta$ than the complex with $\mathrm{NAD}^{+}$. Referring to the earlier mentioned relationship between the hydride-transfer rate and the orientation of the carbonyl dipole, this seems to be in agreement with the observed, reduced rate of the hydride-transfer in the case of PEG$\mathrm{NAD}^{+}[48,52,53]$.

Not satisfying yet is the average value of $\theta$ of only $3^{\circ}$, found for $\mathrm{NAD}^{+} / \mathrm{EtO}^{-}$. It deviates not only from the $\mathrm{X}$-ray value (which might be explained by the fact that ethanol does not resemble DMSO, present in the crystal structure, as well as isopropanol), but also from the results of the quantum calculations. However, the changes we try to explain are very subtle ones. It may be worthwhile to re-examine this detail by repeating the MD calculation in future with an improved file.

A decrease in rate of hydrogen-transfer when ethanol is the substrate may very well have occurred, owing to the changed interactions between enzyme and coenzyme, particularly in this case. It cannot be detected, however, as the dissociation of the coenzyme is the rate-limiting step.

\section{Conclusions}

HLADH appears to be three to four times less active with PEG-NAD ${ }^{+}$than native $\mathrm{NAD}^{+}$. The following explanations for the kinetic behaviour of PEG-NAD ${ }^{+}$can be ruled out as discussed in the corresponding paragraphs:

- A lower intrinsic reactivity

- Interference of singly substituted poly(ethylene glycol) in the enzymatic reaction

- Steric hindrance exerted by the poly(ethylene glycol) tail

- Destabilization of the HLADH dimer.

The reported MD calculations indicate that the PEG-tail of enzyme-bound PEG-NAD ${ }^{+}$causes shifts in the positioning of the coenzyme and of the surrounding peptide chains, owing to the pulling action of the polymer chain. Such changes are evident with both substrates, ethanolate and isopropanolate. Even previous, less accurate calculations, using DMSO as substrate substitute and including fewer water molecules, exhibited similar changes (not shown). Owing to the small differences in energies, needed for these detected conformational changes, the details of the changes may turn out to be different with future improved calculations, but these are unlikely to affect the main conclusion that there are changes of a sufficient extent to cause a three- to fourfold decrease of activity with PEG-NAD ${ }^{+}$. 


\section{Acknowledgements}

PEG-NADH was kindly supplied by Prof. Dr. C. Wandrey and Dr. U. Kragl from the Institute of Biotechnology, Nuclear Research Centre, Jülich, Germany. We thank Dr. H. Haaker from the Agriculture University Wageningen for his aid in carrying out the stopped-flow experiments and Dr. P.D.J. Grootenhuis from Organon for his discussions regarding the modelling calculations.

\section{Appendix A. Competition between two coenzymes $\mathbf{C}_{1}$ and $C_{2}$ at fixed substrate concentration}

\section{A.I. System I: normal competition}

Conservation equation:

$e=E+E C_{1}+E C_{2}$

$e$ denotes the total concentration of subunits. The dissociation constants $K^{\prime}$ of the coenzymes at the chosen substrate concentration are:

$K_{1}^{\prime}=\frac{E \cdot C_{1}}{E C_{1}}$ and $K_{2}^{\prime}=\frac{E \cdot C_{2}}{E C_{2}}$

Insertion into Eq. (1) yields

$e=E\left(1+\frac{C_{1}{ }^{\prime}}{K_{1}}+\frac{C_{2}}{K_{2}^{\prime}}\right)=E \cdot A$

The reaction rate is given by

$v=k_{1}^{\prime} E C_{1}+k_{2}^{\prime} E C_{2}$

in which $k_{1}^{\prime}$ and $k_{2}^{\prime}$ denote the reaction rates with the chosen substrate concentration at infinite coenzyme concentration. Insertion of Eqs. (2) and (3) into Eq. (4) yieldsEq. (5) applies to both options 1 and 3. In the latter case only half of $e$ is available to PEG-NAD ${ }^{+}$but this is then compensated by $k^{\prime}\left(\mathrm{FEG}-\mathrm{NAD}^{+}\right)$being twice as high (see below, system II).

$v=\frac{e}{A}\left(k_{1}^{\prime} \frac{C_{1}{ }^{\prime}}{K_{1}}+k_{2}^{\prime} \frac{C_{2}{ }^{\prime}}{K_{2}}\right)$

\section{A.2. System II: semi competition}

If $C_{1}$ is the coenzyme that is capable of binding to only one of the two subunits (option 2), it means that only half of the subunits can bind both $C_{1}$ and $C_{2}$, according to Eq. (5), and the other half only $C_{2}$. This yields:

$v=\frac{0.5 e}{A}\left(k_{1}^{\prime} \frac{C_{1}}{K_{1}^{\prime}}+k_{2}^{\prime} \frac{C_{2}}{K_{2}^{\prime}}\right)+\frac{0.5 e k_{2}^{\prime}}{1+\frac{K_{2}^{\prime}}{C_{2}}}$

As the experiments were carried out with $10 \mathrm{mM}$ ethanol as substrate, the values $K_{1}^{\prime}=62.0 \mu \mathrm{M}$ and $K_{2}^{\prime}=16.3 \mu \mathrm{M}$ could be taken directly from Table 2 , whereas $k_{1}^{\prime}$ and $k_{2}^{\prime}$ were calculated from their corresponding values of $k_{\text {cat }}$ and $K_{\mathrm{M}}$, providing the ratio $k_{1}^{\prime} / k_{2}^{\prime}=0.30$. If system II is operative, the observed $k_{\text {cat }}$ of PEG-NAD ${ }^{+}$is due to only one of the two subunits and the actual $k_{\text {cat }}$ would be double the one observed. For the calculation of system II the ratio $k_{1}^{\prime} / k_{2}^{\prime}=0.60$ is therefore to be used.

\section{References}

[1] Wang, S.S. and King, C.K. (1979) Adv. Biochem. Eng. 12, 119.

[2] Wichmann, R., Wandrey, C., Bückmann, A.F. and Kula, M.-R. (1981) Biotechnol. Bioeng. 23, 2789-2802.

[3] Wandrey, C. and Wichmann, R. (1985) Biotechnol. Ser. 5, 177-208.

[4] Wandrey, C. (1987) in Proceedings 4th European Congress on Biotechnology (Neijssel, O.M., Van der Meer, R.R. and Luyben, K.Ch.A.M., eds.), Vol. 4, pp. 171-188, Elsevier, Amsterdam.

[5] Kula, M.-R. and Wandrey, C. (1987) Methods Enzymol. 136, 9-21.

[6] Ramaswamy, S., Eklund, H. and Plapp, B.V. (1994) Biochemistry 33, 5230-5237.

[7] Eklund, H., Nordström, B., Zeppezauer, E., Söderlund, G., Ohlsson, I., Boiwe, T., Söderberg, B.-O., Tapia, O. and Brändén, C.-I. (1976) J. Mol. Biol. 102, 27-59.

[8] Eklund, H., Samama, J.-P. and Wallén, L. (1982) Biochemistry 21, $4858-4866$.

[9] Cedergren-Zeppezauer, E., Samama, J.-P. and Eklund, H. (1982) Biochemistry 21, 4895-4908.

[10] Plapp, B.V., Eklund, H., Jones, T.A. and Brändén, C.-I. (1983) J. Biol. Chem. 258, 5537-5547.

[11] Cedergren-Zeppezauer, E. (1983) Biochemistry 22, 5761-5772.

[12] Eklund, H., Samama, J.-P., Wallén, L., Brändén, C.-I. Åkeson Å. and Jones, T.A. (1981) J. Mol. Biol. 146, 561-587.

[13] Eklund, H., Samama, J.-P. and Jones, T.A., (1984) Biochemistry 23, 5982-5996.

[14] Tapia, O. and Eklund, H. (1986) Enzyme 36, 101-114.

[15] Colonna-Cesari, F., Pearlman, D., Karplus, M., Eklund, H., Brändén, C.-I. and Tapia, O. (1986) J. Biol. Chem. 261, 15273-15280.

[16] Horajes, E., Eklund, H. and Brändén, C.-I. (1987) J. Mol. Biol. 197, 685-694.

[17] De Kok, P.M.T., Beijer, N.A., Buck, H.M., Sluyterman, L.A.A. and Meijer, E.M. (1988) Recl. Trav. Chim. Pays-Bas 107, 355-361.

[18] De Kok, P.M.T., Beijer, N.A., Buck, H.M., Sluyterman, L.A.IE. and Meijer, E.M. (1988) Eur. J. Biochem. 175, 581-585.

[19] Beijer, N.A., Buck, H.M., Sluyterman, L.A.Æ. and Meijer, E.M. (1990) Biochim. Biophys. Acta 1039, 227-233; Beijer, N.A., Buck, H.M., Sluyterman, L.A.Æ. and Meijer, E.M. (1990) Ann. N.Y. Ac. Sc. 613, 494-500.

[20] Vanhommerig, S.A.M., Meier, R.J., Sluyterman, L.A.Æ. and Meijer, E.M. (1994) J. Mol. Struct. (Theochem) 304, 53-59.

[21] Biickmann, A.F., Kula, M.-R., Wichmann, R. and Wandrey, C. (1981) J. Appl. Biochem. 3, 301-315.

[22] Sekhar, V.C. and Plapp, B.V. (1990) Biochemistry 29, 4289.

[23] Blankenhorn, G. and Moore, E.G. (1980) J. Am. Chem. Soc. 102, 1092-1098.

[24] Colowick, S.P., Kaplan, N.O. and Ciotti, M.M. (1951) J. Biol. Chem. 191, 447-459.

[25] Pearlman, D.A., Case, D.A., Caldwell, J.C., Seibel, C.L., Singh, U.C., Weiner, P. and Kollman, P.A. (1991) AMBER 4.0, University of California, San Francisco, CA.

[26] Jorgensen, W.L., Chandrasekar, J., Madura, J.D., Impey, R.W. and Klein, M.L. (1983) J. Chem. Phys. 79, 926-935.

[27] QUANTA/CHARMM 3.3.2 is a molecular modelling software package of Molecular Simulations Inc., Waltham, MA. 
[28] Tapia, O., Cardenas, R., Andres, J., Krechl, J., Campillo, M. and Colonna-Cesari, F. (1991) Int. J. Quant. Chem. 39, 767-786.

[29] Weiner, S.J., Kollman, P.A., Case, D.A., Singh, U.C., Ghio, C., Alagona, G., Profeta, S. and Weiner, P.K. (1984) J. Am. Chem. Soc. 106, 765-784

[30] Weiner, S.J., Kollman, P.A., Nguyen, D.T. and Case, D.A. (1986) J. Comp. Chem. 7, 230-252.

[31] CARNAL (beta release) is a coordinate analysis program by, W.S Ross, Dept. of Pharmaceutical Chemistry, UCSF, San Francisco, CA.

[32] Merz, K.M., Jr. (1991) J. Am. Chem. Soc. 113, 4060.

[33] Wratten, C.C. and Cleland, W.W. (1963) Biochemistry 2, 935-941.

[34] Rudolph, F.B. and Fromm, H.J. (1970) Biochemistry 9, 4660-4665.

[35] Dalziel, K. and Dickinson, F.M. (1966) Biochem. J. 100, 34-46.

[36] Brooks, R.L. and Shore, J.D. (1971) Biochemistry 10, 3855-3858.

[37] Vasic-Racki Dj., Jonas, M., Wandrey, C., Hummel, W. and Kula, M.-R. (1989) Appl. Microbiol. Biotechnol. 31, 215-222.

[38] Cleland, W.W. (1979) Methods Enzymol. 63, 103.

[39] Stone et al. (1993) J. Biol Chem. 268, 892-899.

[40] Oppenheimer, N.J., Arnold, L.J. Jr. and Kaplan, N.O. (1978) Biochemistry, 17, 2613-2619.

[41] Al-Karadaghi, S., Cedergren-Zeppezauer, E.S. and Hövmoller, S. (1994) Acta Cryst. D50. 793-807.

[42] Kambe, Y. and Honda, C. (1983) Polymer Communications, 24, $208-210$.

[43] Kambe, Y. and Honda, C. (1984) Polymer Communications, 25, 154-157.
[44] Mosbach, K. and Andersson, L. (1977) in Pyridine Nucleotide-dependent Dehydrogenases, (Sund, H. ed), Walter de Gruyter \& co, Berlin, Germany, p. 173-179.

[45] Beijer, N.A., Buck, H.M., Sluyterman, L.A.E. and Meijer, E.M. (1990) Ann. N.Y. Ac. Sc. 613, 494-500.

[46] Rognan, D., Zimmermann, N., Jung, G. and Folkers, G. (1992) Eur. J. Biochem. 208, 101-113. And references mentioned within this article.

[47] IUPAC-IUB Nomenclature (1983) Eur. J. Biochem. 131, 9-15.

[48] Almarsson, O. and Bruice, T.C. (1993) J. Am. Chem. Soc. 115, $2124-2138$.

[49] D-A $<3.5 \AA$ and $\mathrm{H}-\mathrm{A}<2.5 \AA$ is normally used also in QUANTA.

[50] Vennesland, B. and Westheimer, F.H. (1954) in The mechanism of enzyme action, (McElroy, W.D. and Glass, B. eds), John Hopkins Press, Baltimore, USA.

[51] Eklund, H. and Brändén, C.-I. (1987) in Coenzymes and Cofactors 2A, Pyridine nucleotide coenzymes, (Dolphin, D. ed), John Wiley \& Sons, New York, USA, p. 118-120.

[52] Dutler, H. (1977) in Pyridine Nucleotide-dependent Dehydrogenases (Sund, H., ed.), Walter de Gruyter, Berlin, pp. 339-350.

[53] Donkersloot, M.C.A. and Buck, H.M. (1981) J. Am. Chem. Soc. $103,6554-6558$.

[54] Almarsson, O. and Bruice, T.C. (1993) J. Am. Chem. Soc. 115, 2125-2138.

[55] Vanhommerig, S.A.M., Meier, R.J., Sluyterman, L.A.E. and Meijer, E.M. (1995) J. Mol. Struct. (Theochem), in press. 